\title{
Improved regional selectivity of hepatic arterial mitomycin by starch microspheres
}

\begin{abstract}
Biodegradable starch microspheres, $40 \mu \mathrm{m}$ in diameter, were administered through hepatic arterial catheters in 16 subjects with primary and metastatic liver tumors. These microspheres temporarily obstruct blood flow at the precapillary arteriole (microcirculation) level. Our study was undertaken to determine whether such occlusion would enhance hepatic deposition of, and thereby decrease systemic exposure to, simultaneously administered hepatic arterial mitomycin $C$ (mito). When mito ( $10 \mathrm{mg} / \mathrm{m}^{2}$ over $\left.1 \mathrm{~min}\right)$ was given with $90 \times 10^{6}$ microspheres (10 subjects), there was a $17 \%$ to $70 \%$ reduction in systemic mito exposure. When mito $110 \mathrm{mg} / \mathrm{m}^{2}$ over 1 min) was given with $36 \times 10^{6}$ microspheres (six subjects), there was a $15 \%$ to $60 \%$ reduction in systemic exposure, which may correlate with dose-dependent shunting (8\% to 29\%) through the liver to the lung (and hence to the systemic circulation), attributed to the starch microspheres. No life-threatening myelosuppression was noted; hepatic toxicity consisted of transient pain and elevation of liver enzymes.
\end{abstract}

John W. Gyves, M.D., William D. Ensminger, M.D., Ph.D., Donald VanHarken, Ph.D., John Niederhuber, M.D., Philip Stetson, M.D., Ph.D., and Suzette Walker, R.N.

Ann Arbor, Mich., and Syracuse, N. Y.

Division of Hematology/Oncology, Department of Medicine, and Division of Surgical Oncology,

Department of Surgery, University of Michigan Medical School, Ann Arbor and Bristol

Laboratories, Syracuse

Based on pharmacokinetic principles, it should be possible to markedly increase the drug exposure of tumor within the hepatic arterial watershed by direct hepatic arterial infusion with drugs that have a high total body clearance and short plasma $t^{1 / 2} .^{7,}{ }^{9}$ Fluorouracil and fluorodeoxyuridine (FUDR), ${ }^{15}$ thymidine, ${ }^{11}$ doxorubicin

Supported in part by grants CA28490 and 5-M01-RR-42 from the National Institutes of Health and by the Burroughs Wellcome Foundation.

Received for publication Feb. 1, 1983; accepted Feb. 27, 1983.

Reprint requests to: John W. Gyves, M.D., UpJohn Center for Clinical Pharmacology, University of Michigan Medical School, Ann Arbor, MI 48109.
$\mathrm{HCl},{ }^{18}$ carmustine (BCNU), ${ }^{16}$ dichloromethotrexate, ${ }^{10}$ mitomycin,${ }^{30}$ and cisplatin ${ }^{26}$ have been studied. The need for a reliable and convenient drug delivery system ${ }^{12}$ and a means of determining actual flow distribution to the entire liver, ${ }^{24}, 25,32$ have been recently stressed. The increase in local drug concentration with regional arterial infusions depends largely on blood flow rate in the artery infused. ${ }^{7}$ A low arterial blood flow rate will ensure a high local drug level. The recent availability of degradable starch microspheres (DSM) has allowed study of transient arteriolar-capillary blockade (as a means to decrease blood flow) and the effect of such blockade on the kinetics of concurrent he- 

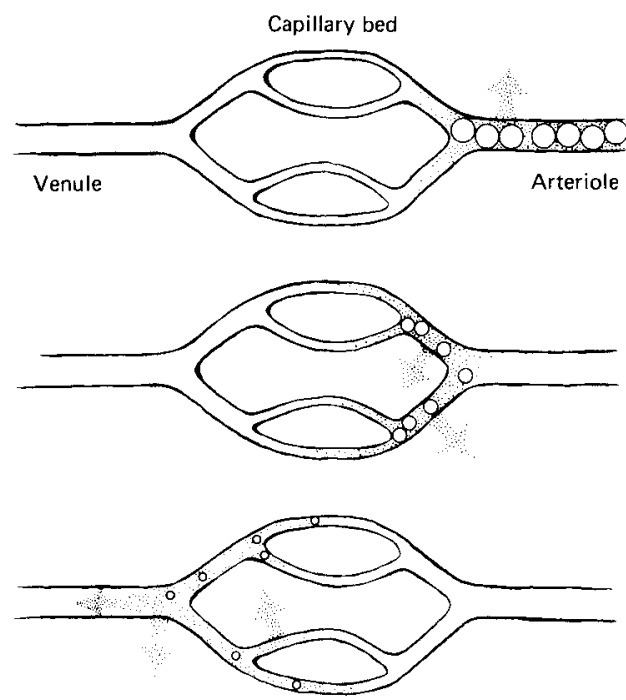

Fig. 1. Schematic representation of starch microscophere-induced precapillary arteriole occlusion and drug egress from blocked blood column. Top, Microspheres (large open spheres) lodged in precapillary arteriole with drug (small dots) movement (arrow) out of blocked blood column. Middle, Movement of microspheres (smaller open spheres) into capillary bed as they are digested, with continued restriction of blood flow and drug movement. Bottom, Further digestion of microspheres (small open spheres) and egress of drug into venule.

patic arterial drug administration. ${ }^{3,8,}{ }^{29}$ In one report, $90 \times 10^{6}$ microspheres with $\mathrm{BCNU}$ in the solution reduced systemic plasma levels of BCNU by as much as $90 \%$ (range $30 \%$ to $90 \%) .{ }^{8}$ This reduction in systemic exposure with DSM implies greater deposition of drug in the organ infused.

When a drug is injected into the hepatic artery, a fraction of the drug diffuses into the surrounding tissue, and another fraction leaks into the systemic circulation. Some drugs, such as $\mathrm{BCNU}$, will also break down spontaneously in plasma. As schematically illustrated in Fig. 1 , when a drug is mixed with starch microspheres and injected into the hepatic artery, the microspheres may cause transient blockage of flow through the capillary bed. The drug is then trapped in a relatively stationary fluid column, allowing more exposure time to the surrounding tissues. With time the microspheres dissolve and the flow through the capillary bed is re-
Table I. Patient characteristics

\begin{tabular}{lc}
\hline Diagnosis & \\
Colorectal cancer & 12 \\
Cholangiocarcinoma & 1 \\
Pancreatic cancer & 1 \\
Gastric cancer & 1 \\
ACUP & 1 \\
Sex & 16 \\
Male & 3 \\
Female & 13 \\
Age (yr) & \\
Range & $40-65$ \\
Median & 53 \\
Mean & 53 \\
\hline
\end{tabular}

ACUP $=$ Adenocarcinoma of unknown primary

stored. For appropriately selected drugs, such an approach may have therapeutic importance based on differences in tumor and normal tissue microcirculation, ${ }^{21}$ but as a result of the obstructed flow, a variable degree of intrahepatic shunting may occur. ${ }^{33}$ The magnitude of the shunt may influence the regional selectivity of such an approach.

The potential for decreased systemic exposure because of increased local hepatic uptake of mito with concurrent hepatic arterial microspheres was examined. Mito was selected because it has activity in a variety of tumors that metastasize to the liver, as well as a short plasma $t^{1 / 2}$ and high total body clearance (characteristics that are essential in the rational use of a drug for regional chemotherapy). ${ }^{7,9.13}$ Myelosuppression is also dose limiting when mito is given systemically. Thus a reduction in systemic exposure when mito is used with microspheres should lead to less myelosuppression with diminished chances for infection and bleeding.

\section{Materials and methods}

The DSM (Pharmacia) consist of specially formulated cross-linked starch spheres $40 \pm 5$ $\mu \mathrm{m}$ in diameter. The degree of cross-linkage is highest in the outer shell, so that the spherical shape is maintained until the final stage of dissolution. The microspheres are degraded by serum amylase and become progressively smaller in size, with a $t^{1 / 2}$ for complete dissolution between 15 and $30 \mathrm{~min}$ in vitro (in normal serum). 
Table II. Effect of starch microspheres $(15 \mathrm{ml})$ on systemic mitomycin exposure (10 subjects; 12 courses)

\begin{tabular}{c|c|c|c}
\hline \multirow{2}{*}{$\begin{array}{c}\text { Interval } \\
(\text { min })\end{array}$} & \multicolumn{2}{|c|}{$\begin{array}{c}\text { AUC }(\mu \mathrm{g} / \mathrm{ml} \cdot \mathrm{min}) \\
\text { mean }(\text { range })\end{array}$} & \multirow{2}{*}{$\begin{array}{c}\text { Signif- } \\
\text { icance }\end{array}$} \\
\cline { 2 - 4 } & Without & With & $\mathrm{P}<0.01$ \\
\hline $0-15$ & 23.40 & 12.94 & $\mathrm{P}$ \\
& $(11.54-33.70)$ & $(5.81-18.35)$ & \\
$0-30$ & 37.64 & 21.50 & $\mathrm{P}<0.01$ \\
& $(17.99-57.02)$ & $(10.46-29.93)$ & \\
$0-60$ & 58.26 & 36.29 & $\mathrm{P}<0.01$ \\
& $(24.44-112.97)(15.86-42.98)$ \\
\hline
\end{tabular}

The spheres are stable in a dry state and can be stored at room temperature. Concentration of the standard DSM suspension is 6 million microspheres $/ \mathrm{ml}(60 \mathrm{mg} / \mathrm{ml})$.

Our subjects were 16 patients with incurable liver tumors (Table I) in whom systemic chemotherapy and hepatic arterial therapy with FUDR had failed. A percutaneous catheter was placed in the hepatic artery through the brachial or femoral route (five subjects), or a Silastic catheter was placed surgically (11 subjects) to perfuse the entire liver as documented by nuclear angiography. ${ }^{24,25,32}$ On two separate days, 10 subjects received mito $\left(10 \mathrm{mg} / \mathrm{m}^{2}\right)$ alone and the same dose reconstituted in $15 \mathrm{ml}$ starch microspheres $\left(90 \times 10^{6}\right.$ microspheres) injected into the hepatic artery catheter over $1 \mathrm{~min}$. This dose of microspheres was based on prior angiographic studies that confirmed transient obstruction of hepatic arterial flow after injection of $90 \times 10^{6}$ particles. Subsequently, six additional subjects were treated with mito $(10 \mathrm{mg} /$ $\mathrm{m}^{2}$ ) with and without $6 \mathrm{ml}$ starch microspheres (36 $\times 10^{6}$ microspheres) to evaluate the effect of shunting through the liver on systemic drug exposure. Peripheral venous blood samples were obtained at $0,1,2,4,6,8,10,15,20,30,45$, and $60 \mathrm{~min}$ after injection on each occasion, and the plasma was assayed for mito by a sensitive microbiologic assay or HPLC. The AUC with time was used as a measure of systemic exposure. Complete blood counts and liver enzyme determinations were obtained weekly to monitor toxicity.

Before treatment, the flow distribution to the

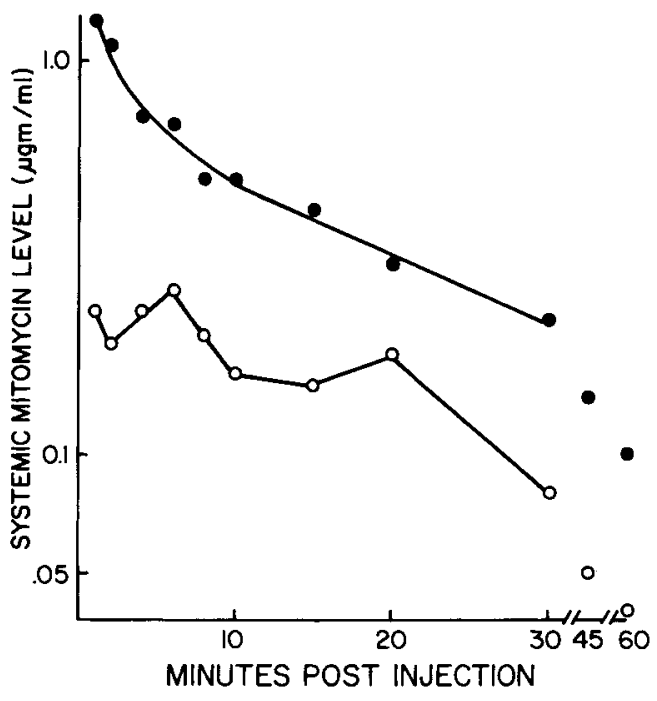

Fig. 2. Effect of starch microspheres on systemic mito level with hepatic arterial injection. Mito alone $(\bullet-\bullet)$; mito with $90 \times 10^{6} \mathrm{DSM}(\circ-0)$.

entire liver was determined by injecting $4 \mathrm{mCi}$ of technetium $99 \mathrm{~m}$ macroaggregated albumin (TcMAA) over 1 min through the hepatic arterial catheter. ${ }^{24,}{ }^{25}$ These TcMAA particles are approximately $35 \mu \mathrm{m}$ in size and are trapped in the first precapillary arteriole encountered. Thus scans obtained after such injection reflect the microcirculation patent at the time of injection.

A 15-ml suspension of starch microspheres was mixed with $5 \mathrm{mCi}$ TcMAA and aliquoted into five 3-ml syringes, each containing equal amounts of tracer and microspheres. One millicurie TcMAA was injected into the hepatic artery to obtain a baseline nuclear angiogram. Thereafter, repeated 3-ml doses of TcMAAspiked starch microspheres were injected through the hepatic artery, allowing sufficient time ( $1 \mathrm{~min}$ ) between doses to obtain scintillation data over the liver, abdomen, and lungs. Based on these data, changes in the amount of isotope (counts) delivered to the entire liver and areas outside the liver (lung and stomach and/or small bowel) can be calculated at each dose and a percent shunt index (PSI) determined. The PSI was calculated as:

$$
\text { PSI }=\frac{\text { Total field counts }- \text { liver counts }}{\text { Total field counts }} \times 100 \%
$$


Table III. Ratio of systemic mitomycin exposure (AUC) with $(15 \mathrm{ml})$ microspheres and without microspheres (10 subjects; 12 courses)

\begin{tabular}{c|c|c|c}
\hline $\begin{array}{c}\text { Subject } \\
\text { No. }\end{array}$ & $0-15 \mathrm{~min}$ & $0-30 \mathrm{~min}$ & $0-60 \mathrm{~min}$ \\
\hline 1 & 0.66 & 0.66 & 0.69 \\
& 0.70 & 0.71 & 0.75 \\
2 & 0.67 & 0.68 & 0.70 \\
& 0.52 & 0.58 & 0.62 \\
3 & 0.54 & 0.58 & 0.64 \\
4 & 0.46 & 0.49 & 0.54 \\
5 & 0.53 & 0.61 & 0.64 \\
6 & 0.59 & 0.58 & 0.54 \\
7 & 0.50 & 0.58 & 0.65 \\
8 & 0.88 & 0.85 & 0.83 \\
9 & 0.30 & 0.36 & 0.36 \\
10 & 0.41 & 0.36 & 0.28 \\
Mean & 0.56 & 0.59 & 0.60 \\
\hline
\end{tabular}

Subjects with evidence of flow to the stomach and/or small bowel were excluded from treatment, as were those with a baseline shunt of more than $30 \%$ of activity going to lung.

A microbiologic assay with $E$. coli inoculation of BBL seed agar incubated at $30^{\circ}$ for 16 to $18 \mathrm{hr}$ was performed at Bristol Laboratories. This assay was used to measure plasma mito levels in the first 10 subjects treated with $15 \mathrm{ml}$ DSM. The lower limit of the assay is 0.01 $\mu \mathrm{g} / \mathrm{ml}$.

An HPLC assay has been developed for the determination of mito in human plasma. The method involves extraction of mito into an organic solvent, injection of 2 to $20 \mu 1$ for HPLC analysis on a $\mu$-Bondapak $C_{18}$ reverse-phase column (Waters), and detection on a UV detector at $365 \mathrm{~nm}$ wavelength. Quantitation was with an internal standard (porfiromycin) by the peak/height ratio method. This assay was used to measure plasma mito levels in the group of six subjects treated with $6 \mathrm{ml}$ DSM. The lower limit of the assay is $25 \mathrm{ng} / \mathrm{ml}$.

\section{Results}

Fig. 2 shows the systemic mito concentration-time profile in one representative subject (Table III, subject 8) after hepatic artery injection of mito alone and after mito with $15 \mathrm{ml}$ microspheres. AUCs were calculated as repre- sentative of relative systemic drug exposure. The ratio of AUC with mito plus microspheres and mito alone over $1 \mathrm{hr}$ was 0.83 , in this case indicating approximately $20 \%$ reduction in systemic exposure when mito was injected with DSM.

Table II shows the effects of concurrent DSM on systemic mito exposure compared with hepatic arterial mito alone in 10 subjects. Two subjects were treated on two separate occasions. At each of the time intervals indicated, there was a reduction in the mean AUC when mito was injected with DSM. The effect was signifcant (paired t test, $\mathrm{P}<0.01$ ). ${ }^{6}$ Table III shows the ratio of systemic exposure (AUCs) when mito is injected with DSM and when mito alone is given to each of these patients. In this group of patients there was some variability in the ratio of the AUCs, but in all cases there was a reduction in systemic exposure $(17 \%$ to $70 \%)$ when mito was injected with DSM. There was a mean reduction in systemic exposure of $40 \%$ to $45 \%$ over $1 \mathrm{hr}$.

All subjects in this study received treatment with mito alone, followed by treatment with mito and DSM on a separate day. In order to exclude the possibility that the first dose of mito alone might influence the elimination of a subsequent dose, we measured plasma drug levels in four other subjects receiving mito (10 $\mathrm{mg} / \mathrm{m}^{2}$ ) alone on two consecutive days. In these cases there was an average $6 \%$ change in the systemic exposure (median $5.9 \%$, range $0.7 \%$ to $10.4 \%$ ) by prior treatment. In addition, in a second treatment course one of the 16 subjects subsequently received mito with DSM, followed by mito alone on a second day. The results confirmed the lack of a sequential dose effect (data not shown).

During the course of this investigation, all subjects underwent baseline nuclear angiography with TcMAA microspheres alone. In subsequent studies we observed significant intersubject variability in shunting through the liver to the lungs when TcMAA microspheres were subsequently injected with $15 \mathrm{ml}$ DSM. Based on this observation and the variability in reduction of systemic exposure noted in the first 10 subjects, we subsequently treated an additional six subjects with mito $\left(10 \mathrm{mg} / \mathrm{m}^{2}\right)$ alone and with DSM on separate days. Before treatment, 
however, these subjects were scanned after the incremental doses of DSM spiked with TcMAA. This allowed us to determine the shunting (PSI) that occurred with increasing DSM doses ( 0 to $90 \times 10^{6}$ microspheres $)$ in the individual subjects. These six subjects (Table IV) then received mito alone and mito with $6 \mathrm{ml}$ $\left(36 \times 10^{6}\right.$ microspheres) DSM. Based on the incremental study, in all cases the magnitude of the shunt at this dose of DSM was known. The PSI ranged from $8 \%$ to $29 \%$ (mean $17.2 \%$ ). Systemic exposure to mito (AUC) on both days was measured. Under these circumstances, the variability in reduction of systemic exposure (ratio of AUCs) seen in the first group of subjects was observed again. The reduction in exposure averaged about $35 \%$ (range $15 \%$ to $60 \%$ ) in these subjects. There was some tendency for the reduction in systemic exposure to correspond to the magnitude of the shunt, although a larger number of subjects will be needed to confirm this.

In all subjects the toxicity was limited to non-life-threatening myelosuppression (three cases), transient rise in liver chemistries (eight cases), nausea (six cases), and pain in the right upper quadrant (three cases). Based on liver chemistry determinations there was subsequent improvement in liver function in all subjects. No objective response was seen in these heavily pretreated subjects.

\section{Discussion}

Liver involvement by cancer occurs frequently and is a major cause of death. Although most patients with primary hepatobiliary and metastatic tumors in the liver cannot be cured with surgical resection, some are, indicating regional confinement in such cases. ${ }^{17},{ }^{27}$ In other cases, the cancer may be confined to the liver and yet may be surgically unresectable because of anatomic location. ${ }^{17}, 19,27,28$ Thus other effective methods for eradicating tumor liver may cure some patients and palliate the effects of the tumor in many more.

The liver has a dual blood supply, and under normal circumstances, approximately one third of blood entering the liver comes from the hepatic artery and two thirds from the portal vein. ${ }^{20,} 31 \mathrm{~A}$ number of investigations have shown that hepatic tumors derive most of their
Table IV. Ratio of systemic mitomycin exposure (AUC) with $(6 \mathrm{ml})$ microspheres and without microspheres (six subjects)

\begin{tabular}{c|c|c|c|c}
\hline $\begin{array}{c}\text { Subject } \\
\text { No. }\end{array}$ & PSI & $0-15 \mathrm{~min}$ & $0-30 \mathrm{~min}$ & $0-60 \mathrm{~min}$ \\
\hline 1 & 8 & 0.42 & 0.42 & 0.48 \\
2 & 10 & 0.56 & 0.64 & 0.67 \\
3 & 10 & 0.58 & 0.60 & 0.66 \\
4 & 21 & 0.52 & 0.65 & 0.73 \\
5 & 25 & 0.76 & 0.72 & 0.68 \\
6 & 29 & 0.85 & 0.82 & 0.82 \\
Mean & 17.2 & 0.62 & 0.64 & 0.67 \\
\hline
\end{tabular}

blood from the hepatic artery. ${ }^{2,}$ 4. 5. ${ }^{2.3}$ On the other hand, the liver parenchyma is able to survive and function on the portal blood supply alone. Thus the liver has served as a useful model for the development of new techniques and approaches to regional therapy. Recent developments in drug delivery techniques make possible a variety of clinical pharmacologic studies based on selective manipulation of the tumor microvasculature. ${ }^{12,}{ }^{14} \mathrm{TcMAA}$ has been given by hepatic arterial injection to patients with liver tumors to determine drug flow distribution. ${ }^{24,}{ }^{25}$ These albumin particles (30 to 40 $\mu \mathrm{m}$ in diameter) are held in the first precapillary arteriole they encounter. Thus the relative density of TcMAA should relate directly to the relative density of the microcirculation patent at the time of injection. Angiographically hypervascular and hypovascular tumors both appear to trap more TcMAA than the surrounding normal liver (as defined by technetium- $99 \mathrm{~m}$ sulfer colloid ( $\mathrm{TcSC}$ ) liver scans). Many small tumor nodules appear to be uniformly hypervascular, whereas larger nodules appear to have a rim of increased activity surrounding a relatively hypovascular core. ${ }^{21}$ This observation corresponds to the findings of others that suggest that the areas of active tumor proliferation at the periphery of tumor nodules are vascular. ${ }^{1,5}$

Biodegradable starch microspheres, $40 \mu \mathrm{m}$ in diameter, have been introduced into cancer therapy. $3,8,29$ When injected into the hepatic artery, they lodge in the microvasculature and can block flow for 15 to $30 \mathrm{~min}$. Coincident with this obstruction, intrahepatic shunting may 
occur. The magnitude of the shunting appears to be related to the dose of DSM, although a significant baseline shunt may also be present. ${ }^{33}$ As expected, the shunt may adversely affect the reduction in systemic exposure and ultimately will determine the optimal dose of DSM selected for therapy. This finding may have implications for the design of other studies involving hepatic arterial drug injection. Administration of an optimal quantity of starch microspheres in an appropriate drug solution should lead to a holdup of the drug solution in the microcirculation. Because this obstruction is temporary, repeated treatment is possible. Delivery of the drug solution within the tissue should be proportional to the microcirculation volume, which is proportional, in turn, to the number of microspheres entrapped in a given region of the tissue analogous to the TcMAA studies.

Finally, in previous studies hepatic extraction of mito was found to be $5 \%$ to $10 \%$ by direct arteriovenous sampling and by a comparison of systemic exposure with intravenous and hepatic arterial administration. ${ }^{22}$ From our report it can be seen that microspheres induce a fourfold to ninefold increase in hepatic mito deposition and extraction (from $5 \%$ to $10 \%$ to $40 \%$ to $45 \%$ ). Unlike mito, BCNU is known to break down spontaneously in plasma. This may explain the difference in enhanced regional selectivity when each of these drugs is given with DSM. The absence of significant hepatotoxicity or myelosuppression is encouraging. An attempt to exploit this improved regional selectivity with repeated doses of hepatic arterial mito with microspheres is under way.

\section{References}

1. Ackerman NB, Hechmer PA: The blood supply of experimental liver metastases. V. Increased tumor perfusion with epinephrine. Am J Surg 140: 625-631, 1980.

2. Almersjo O, Bengmark S, Engevik L, Hafström L, Nilsson L: Hepatic artery ligation as pretreatment for liver resection of metastatic cancer. Rev Surg 23:377-380, 1966.

3. Aronsen KF, Hellenkant C, Holmberg J, Rothman U, Teder $\mathrm{H}$ : Controlled blocking of hepatic artery flow with enzymatically degradable microspheres combined with oncolytic drugs. Eur Surg Res 11:99-106, 1979.
4. Bierman HR, Byron RL, Kelley KH, Grady A: A. Studies on the blood supply of tumors in man. III. Vascular patterns of the liver by hepatic arteriography in vivo. J Natl Cancer Int 12:107-117, 1951 .

5. Breedis C, Young G: Blood supply of neoplasms in the liver. Am J Pathol 30:969-977, 1954.

6. Brown BW, Hollander M: Statistics: A biomedical introduction. New York, 1977, John Wiley and Sons, Inc.

7. Chen HSG, Gross JF: Intra-arterial infusion of anticancer drugs: Theoretic aspects of drug delivery and review of responses. Cancer Treat Rep 64:31-40, 1980.

8. Dakhil S, Ensminger WD, Cho K, Niederhuber J, Doan K, Wheeler R: Improved regional selectivity of hepatic arterial BCNU with degradable microspheres. Cancer 50:631-635, 1982.

9. Eckman WW, Patlak CS, Fenstermacher JD: A critical evaluation of principles of governing the advantages of intra-arterial infusions. J Pharmacokinet Biopharm 2:257-285, 1974.

10. Ensminger WD, Dakhil S, Doan K, Cho K, Wheeler R, Pollard HM: Clinical pharmacology of dichloromethotrexate in hepatic arterial infusions. Proc AACR/ASCO 22:271, 1981 .

11. Ensminger WD, Frei E III: High-dose intravenous and hepatic artery infusions of thymidine. Clin Pharmacol Ther 24:610-615, 1978.

12. Ensminger WD, Gyves J: Clinical pharmacology of hepatic arterial chemotherapy. Semin Oncol 10:176-182, 1983

13. Ensminger W, Gyves J: Regional chemotherapy of neoplastic disease. Pharmacol Ther. (In press.)

14. Ensminger W, Niederhuber J, Dakhil S, Thrall J, Wheeler R: Totally implanted drug delivery system for hepatic arterial chemotherapy. Cancer Treat Rep 65:393-400, 1981.

15. Ensminger WD, Rosowsky A, Raso V, Levin DC, Glode M, Come S, Steele G, Frei E III: A clinical-pharmacological evaluation of hepatic arterial infusions of 5-fluoro-2'-deoxyuridine and 5-fluorouracil. Cancer Res 38:3784-3792, 1978.

16. Ensminger WD, Thompson $M$, Come S, Egan EM: Hepatic arterial BCNU: A pilot clinicalpharmacologic study in patients with liver tumors. Cancer Treat Rep 62: 1509-1512, 1978.

17. Fortner JG, Dong KK, Maclean BJ, Barrett MK, Iwatsuki S, Turnbull AD, Howland WS, Beattie EJ: Major hepatic resection for neoplasia. Ann Surg 188:363-371, 1978.

18. Garnick MB, Ensminger WD, Israel $\mathrm{M}$; $\mathrm{A}$ clinical-pharmacological evaluation of hepatic arterial infusion of adriamycin. Cancer Res 39:4105-4110, 1979

19. Geddes EW, Falkson G: Malignant hepatoma in the Bantu. Cancer 25:1271-1278, 1970.

20. Grindlay JH, Herrick JF, Mann FC: Measure- 
ment of the blood flow of the liver. Am J Physiol 132:489-496, 1941.

21. Gyves J, Ensminger W, Thrall J, Cho K, Walker $S$ : Dependence of hepatic tumor vascularity on tumor size. Clin Res 30:747A, 1982.

22. Gyves JW, Ensminger WD, Stetson P, VanHarken D, Janis M, Cho K, Meyer M, Walker S, Gilbertson S, Niederhuber J: Clinical pharmacology of mitomycin $\mathrm{C}$ (mito) by hepatic arterial (HA) infusion. Proceedings, American Society of Clinical Oncology 2:25, 1983.

23. Healy JE: Vascular patterns in human metastatic liver tumors. Surg Gynecol Obstet 120:1187$1193,1965$.

24. Kaplan WD, D'Orsi CJ, Ensminger WD, Smith $\mathrm{EH}$, Levin D: Intra-arterial radionuclide infusion: A new technique to assess chemotherapy perfusion patterns. Cancer Treat Rep 62:699$703,1978$.

25. Kaplan WD, Ensminger WD, Come SE, Smith EH, D'Orsi CJ, Levin DC, Takvorian RW, Steele GD: Radionuclide angiography to predict patient response to hepatic artery chemotherapy. Cancer Treat Rep 64:1217-1222, 1980.

26. Kelsen DP, Hoffman J, Alcock N, Cheng E, Golbey RB, Young CW, Fortner J: Pharmacokinetics of cisplatin regional hepatic infusions. Proc Am Assoc Cancer Res 21:745, 1980.

27. Latham F Jr, Foster JH: Hepatic resection for metastatic cancer. Am J Surg 113:551-557, 1967.
28. Lee YT: Systemic and regional treatment of primary carcinoma of the liver. Cancer Treat Rev 4:195-212, 1977.

29. Lindell B, Aronsen KF, Nosslin B, Rothman U: Studies in pharmacokinetics and tolerance of substance temporarily retained in the liver by microsphere embolization. Ann Surg 187:95-99, 1978.

30. Tseng MH, Luch J, Mittelman A, Ledesma EJ, Berjian RA: Chemotherapy of advanced colorectal cancer with regional arterial mitomycin $C$ infusion and concomitant measurement of serum drug level. Proc AACR/ASCO 22:359, 1981.

31. Tyastrup N, Winkler K, Mellemgaard K, Andereassen M: Determination of the hepatic arterial blood flow and oxygen supply in man by clamping the hepatic artery during surgery. J Clin Invest 41:447-454, 1962.

32. Yang PJ, Thrall JH, Ensminger WD, Niederhuber JE, Gyves JW, Tuscon M, Doan M, Cozzi E: Tc $99 \mathrm{~m}$ macroaggregated albumin perfusion scintigraphy for intraoperative hepatic artery chemotherapy catheter placement. J Nucl Med 23:1066-1069, 1982

33. Ziessman HA, Thrall JH, Ensminger WD, Gyves JW, Niederhuber JE, Tuscon M, Walker $S$ : Quantitative hepatic arterial perfusion scintigraphy and starch microspheres in cancer chemotherapy. J Nucl Med, 1983. (Submitted for publication.) 